\title{
WOMEN ONLY? AN EXPLORATION OF THE PLACE OF MEN WITHIN
}

\section{NURSING}

by

\author{
Mark Entwistle
}

A research project submitted to the Victoria University of Wellington in partial fulfillment of the requirements for the degree of Master of Arts (Applied) in Nursing

Victoria University of Wellington 2004 


\begin{abstract}
This dissertation came out of my wondering why there are still so few men going into nursing especially when one considers that the history of nursing reveals men have been a part of nursing for a long time. In New Zealand it is only since the mid seventies that men have been able to gain the exact same nursing qualifications as their women colleagues.
\end{abstract}

Men in nursing are still seen as unusual in that they work in a predominantly female occupation and have had their masculinity questioned by the myth that all men in nursing must be gay. There is also the notion that caring is a difficult task for men and is seen by society as a uniquely feminine ability. Both issues are related to dominant notions of masculinity. In addition to this there is currently a crisis in terms of a nursing shortage and it has been suggested that one way to resolve this crisis is to encourage more men into nursing. Thus this exploration as to why there are so few men in nursing is timely.

Men who choose nursing as a career risk challenging the traditional roles of their gender stereotype. A comprehensive search of the literature from different disciplines reveals deeper issues than just the commonly held assumption that nursing is not masculine. Exploring the issues of gender with a particular focus on masculinity has uncovered the concept of hegemonic masculinity. This describes how gender is practiced in a way that legitimises patriarchy, reinforcing the dominant position of men over 
women as well as over other groups of men. It is these patriarchal attitudes that have seen men marginalised within nursing. On the one hand men in nursing could be seen as challenging the current dominant masculine ideal. However, on the other hand men in nursing may not challenge this hegemonic masculinity; instead often supporting the status quo in an effort to maintain their own masculinity.

The implication for nursing, if it is to increase the numbers of men in the profession, is to challenge this notion of hegemonic masculinity. This needs to be done appropriately by critically examining this concept rather than by merely replacing one hegemony with another. A greater awareness of how hegemonic masculinity and notions of gender have historically affected, and continue to affect the development of nursing is important. However, issues of gender and masculinity have often been overlooked in nursing education. It is now time for nursing education to include a critical exploration of gender issues and how it relates to men as part of undergraduate nursing education for both men and women students. 


\section{Acknowledgments}

I would like to thank the following people for their assistance in making this dissertation possible:

Brian Phillips for all his mentoring, encouragement, support and valuable feedback throughout the past two years.

John Fenaughlty, Sue Johns, Steph Maddenholt-Titley, and Monique Redmond for reading the final drafts, and for providing feedback with the wisdom that they bring from their own distinct fields of learning.

My parents, Barbara and Peter, for their support, assistance and their belief that I could complete this degree.

And a big thank you to my daughter Hillary who has put up with my absences, my grumpiness and my vagueness throughout the year. Without you cooking dinner and telling me to go and study I might never have finished. 


\section{Table of Contents:}

$\begin{array}{ll}\text { Introduction } & 1\end{array}$

'Male Nurse' or 'Men in Nursing'? A position 2

Section 1. Men in Nursing: A Brief History 4

Section 2. Gender, Masculinity and Nursing

The construction of gender and masculinity 12

Hegemonic Masculinity. Its effect on men in nursing

$\begin{array}{ll}\text { and on nursing } & 15\end{array}$

$\begin{array}{ll}\text { Maintaining masculinity } & 17\end{array}$

Why did it taken so long for men to be accepted as

legitimate nurses in NZ? The effects of hegemonic masculinity. 21

Tokenism: How token men are advantaged in Nursing. 24

Men in nursing management positions 26

Section 3. Being a man in nursing

Stereotyping: “All men in nursing are gay” 30

Learning to Care 35

Section 4. Recruiting and retaining men in nursing

Why men enter nursing $\quad 40$

$\begin{array}{ll}\text { Support } & 44\end{array}$

$\begin{array}{ll}\text { Conclusion } & 47\end{array}$

$\begin{array}{ll}\text { References } & 52\end{array}$ 


\section{Introduction}

Women have been successful in making inroads into traditionally male dominated occupations, especially since the 1970's. This has resulted in a greater career choice for women. On the other hand, however, men do not seem to be crossing over into traditional female dominated professions such as nursing. This dissertation came out of my wondering why this is so: that there are still so few men going into nursing. In addition to this there is currently a crisis in terms of a nursing shortage and it has been suggested that one way to resolve this crisis is to encourage more men into nursing. Thus such an exploration as to why there are so few men in nursing would appear timely.

This dissertation will explore the reasons in detail why men do not enter nursing. Current literature from nursing as well as other academic disciplines will be used to inform the discussion. The exploration moves beyond the seemingly obvious answer that nursing is not manly enough to attract significant numbers of men into the profession. The meaning of this manliness will be examined through an exploration of the two concepts of gender and masculinity. This exploration will consider a historical context, as the place men occupy within nursing is tied to historical and contemporary notions of gender and masculinity both internationally and within New Zealand. 
The advantages that men have within nursing will be explored, particularly in the ability to move up the hierarchical ladder into administrative positions. The concept of tokenism will be introduced and this together with dominant notions of masculinity will be used to understand why men are better represented in nursing management

This dissertation will also explore the following two issues. The first is that men in nursing are seen as unusual in that they work in a predominantly female occupation and may have their masculinity questioned, notably by the myth that all men in nursing must be gay. The second is the notion that caring is a difficult task for men and is seen as a uniquely feminine ability. Both issues will be looked at in the context of dominant notions of masculinity.

Of interest to me as a nurse educator, is why men do enter nursing and once there, how they experience becoming enculturated into nursing. The exploration of this, alongside issues of retention especially in terms of the support men may require within nursing will be discussed. As a conclusion the implications of the ideas discussed in this dissertation will be presented with some recommendations made for both practice and education.

\section{Male Nurse' or 'Men in Nursing'? A position}

The reader will note that the term 'male-nurse' has not been used in this dissertation. The reason for this, as Egeland and Brown (1988) suggest, is the use of the term 'male' implies that men in nursing are different and not 
in keeping with the norm in society. Women in nursing are simply 'nurses' not 'female nurses'. The term male nurse suggests a sub-type or subclassification and thus it would appear that men who nurse fail to fit into the expected role norms and as a result the term 'male nurse' has been created to accommodate this malfit (Fitzgerald, 1995). In placing a gender descriptor such as male before the term 'nurse' the term 'male nurse' functions as a cue for the amendment to the stereotype 'nursing is a female occupation'. This only reinforces the idea that a man cannot be a nurse but only a sub-type of nurse - 'a male nurse'.

Groff (1984) describes the term 'male nurse' as demeaning as it suggests this person is a member of a sub-species of nurse and, merely on the basis of gender, is not the real thing. This writer suggests that there is some regret from patients regarding care from a nurse who is a man; there is an assumption that the patient will miss out on being comforted and also on some routine aspects of nursing care such as back-rubs. The underlying assumption here is an image of a nurse who has the power to dominate over their patients in a way that the feminine cannot and that the man will dismiss their needs because men are unable to care.

This dissertation will explore the reasons why men within nursing have been labeled as such by examining notions of gender and masculinity. To place this within the context of today's practice it is necessary to look firstly at the history of men within nursing. 


\section{Section 1. Men in Nursing: A Brief History}

To place the literature in context, it is worth noting that men have been a part of nursing for a long time, their caring dating back at least to the middle ages (Polifacio, 1998). According to Mackintosh (1997) men were an accepted part of what was then known as nursing in the Middle Ages, where they were often part of the monastic institutions. There is historical evidence that men were carers in the voluntary hospitals and in the poor workhouses of early Victorian England (Carpenter, cited in Mackintosh, 1997).

The development of modern nursing by Florence Nightingale effectively removed men from nursing within the voluntary hospitals (Polifacio, 1998). Nightingale saw it as natural for nursing to be undertaken by women, a reflection on the societal views of the period. Whilst this did much for creating an acceptable and respectable work role for Victorian women (Mackintosh, 1997), it began to exclude men from the general nursing workforce. Here it is important to briefly examine the place of women in the industrial revolution (1750-1830) and in the Victorian period (1837-1901) in England.

During the industrial revolution, women who worked were seen as taking jobs away from the men and thus it was seen as necessary to displace those women in favour of men (Bullough, 2001). Women who had to work gained positions as domestics and washerwomen, tasks now long regarded 
as belonging to a women's world. These positions were not, however, available to middle and upper-class women in class conscious Victorian England. During this time women were seen as being made of delicate and finer material and they had to be protected as the real world could easily destroy or weaken them. Such a portrayal bore little resemblance to the real world of working class women, but the portrayals were endorsed by the science and religion of the time, especially for upper and middle class women. For these women, the problem was to break through these barriers and yet still retain a 'proper' feminine image. The obvious solution was to make the traditional women's activities in the home into a profession (Garmarnikow 1991).

Those women who wanted to challenge traditional gender views seized on the $19^{\text {th }}$ century notion that they constituted a special class and used this to their advantage. Into this came Nightingale, a woman of independent wealth who did not want to marry and turn her fate over to a man (Bullough, 2001). Money was of no concern to her and consequently was not a consideration in what she chose to do professionally. To Nightingale nursing was the answer as it allowed her to maintain an image of a 'proper woman' yet still be on her own. This type of employment differed from women's previous activities in that nursing was no longer domestic service but redefined as healthcare. These changes had the potential to alter the nature of the nurse-doctor relationship and thus challenged medical predominance in healthcare (Garmarnikow, 1991). According to Garmarnikow this transformation was institutionalised into a unified 
hierarchical nursing department and a hospital based system of nurse training. By emphasising the feminine aspects of the job over the actual work, nursing sought to keep the occupation under women's control as Nightingale initially planned. However, this effectively created a block to access for those men that wanted to go nursing.

It could be said that it was also in medicine's best interests to argue that women were uniquely qualified to nurse. Since nurses were subordinate to doctors and women to men, 'natural' female subservience to men could secure professional subservience to medicine and thus ensure the balance of power remained with men. Consequently, as Garmarnikow (1991) states, the nurses' skills and abilities were collapsed into women's obedience to the male doctor. Because nursing was a profession dominated by women, it was easy to economically exploit nursing students by stressing Victorian attitudes of the period that called for subservient behaviour on the part of women and stress the danger of too much education to women's essential maternal functions (Hoff, 1991). These factors, according to Hoff, helped support the social and ideological forces that shaped the development of modern hospitals and the medical profession.

Due to the economic advantage of the nursing apprenticeship system to hospitals and the medical profession, hospital and medical organisations together exerted powerful control over attempts by nursing to reform and take control of nursing education (Hoff, 1991). Admitting men into nursing 
would question the submissive role of the nurse. In such an environment it is little wonder that for the next 90 or so years men were to be excluded or at least discouraged from entering nursing.

The exclusion of men in the formative years of modern nursing (1852 onwards) established a pattern that has become deeply entrenched in both nursing and the wider society (Mackintosh, 1997). In the United Kingdom, men were actively discouraged from entering nursing with the Nursing Registration Act of 1919 offering only women entry to the Register. Men instead, were only eligible to be admitted to parts of the register (Mackintosh). It was not until the post war period, when there was a shortage of nurses that a subsequent review of nursing suggested that both men and women should be allowed entry to all parts of the register (Brown, Nolan \& Crawford, 2000). In the period 1939-1947 there was a 542\% increase in the number of men registering as nurses in the UK (Brown, Nolan and Crawford).

The post-war nursing shortages and equally the job shortages for returned servicemen meant that there was a swift recruitment of men into the general hospitals. However, this increase was short lived and by the late 1960's the number of men in nursing had fallen again. This, as Mackintosh (1997) points out, is possibly due to three factors. The first was that the belief in the natural nature of nursing as a woman's occupation still remained. This produced contradictory assumptions about men in nursing: that the introduction of men in nursing was an attempt in some way to 
violate the respectability of the occupation, and that, because men were supposedly not naturally capable of performing caring nursing activities, men in nursing could therefore not be 'real men' and definitely not 'real nurses'. The second factor was the poor working conditions with long hours and low pay which was discouraging both women and men. Thirdly, the inability to shake off the low reputation that men in nursing had acquired as a consequence of their long association with less respectable areas of nursing work such as custodial work in psychiatric hospitals, meant that even fewer men were attracted to nursing (Mackintosh). A study in the early 1970's in the United Kingdom into men in nursing found that several hospitals indicated that they considered men in nursing to have only a limited role in general nursing and were not prepared to accept men for training who did not display at least as strong a motivation as their women recruits (Brown \& Stones, 1973). This could also be a contributing factor in the lack of men in nursing even up to the 1970's.

Men in nursing fared a little better in the United States of America where they were able to register as a nurse. However, education was strictly segregated into separate schools for men and women, with some colleges preventing men from entering the profession right up until the 1980's (Polifacio, 1998).

In North America many schools of nursing frequently refused to employ men nursing instructors on the grounds that it was not 'proper' for men to teach women how to nurse (Wedgery, cited in Evans, 2004). As Evans 
points out, there is an implied message here that it is unnecessary and inappropriate for men to teach women how to do that which comes naturally to them. Whether the same restrictions for men were in place in New Zealand is not known, but assuming similar patriarchal cultural values and the absence of any documented men nurse tutors, one can assume that some of this thinking was prevalent in this country. The absence of men in nursing education would have further alienated many men from nursing when one considers Williams’ (1995) research findings that men students in 'non-traditional' occupations often found support and mentorship from the men teachers in their respective faculties.

The history of men in Nursing in New Zealand followed a similar path to that of the UK, although in this country it took men a lot longer to be able to be recognised as a nurse like their women colleagues. The Nurses Registration Act of 1901 specifically excluded men from entering the Register. The large-scale entry of men into general nursing might have unsettled the subordinate relationship of nursing to medicine, a relationship that was, as we have seen, endorsed by nursing's female workforce and medicine's male one (Savage, 1987). It was not until 1939 and an amendment to the Nurses and Midwives Act (1925) that men were able to be admitted to the New Zealand Nurses Register (Harding, 2003a). At this stage men were only offered a two-year in-hospital course, thus ensuring that the place of men was only as a type of second level nurse (Brown, 1994). This two-year course was despite the fact a provision for a threeyear programme for men was provided for in the 1945 Nurses Act. 
Men were also excluded from joining the New Zealand Registered Nurses Association. In 1948 The Society of Registered Male Nurses was formed to look after the concerns of the men within nursing. During the 1950's a push was made by the Society for a three-year training programme as per the 1945 Nurses Act. The Society was also concerned about the quality of education and wanted students to be trained at 'A' grade hospitals (Brown). At this time training for men was only offered at 'B' grade hospitals such as Burwood in Christchurch and Cornwall in Auckland. ${ }^{1}$ The Director General of Health was lobbied and, with the support from two women MP's, the three-year curriculum was finally offered in 1958 (Brown). The three-year curriculum, however, continued to segregate men in their education and their practice by being offered a separate training with the qualification of Registered Male Nurse. This excluded them from obstetrics and paediatrics, with students being given extra time in geriatrics and in male genitourinary nursing (Brown). As one nurse from that time recalled, “we were seen as either gay, paedophiles or rampant heterosexuals. We weren't allowed near women. We weren't allowed near children. They couldn't make up their minds where they should put us” (Fraser, quoted in O’Connor, 2003, p.20).

The educational inequality continued in New Zealand until the late 1970's when an amendment to the Nurses Act in 1977 finally allowed men to fully participate "in the full scope of nursing activity" (Harding, 2003a, p.19).

\footnotetext{
1 "A" grade hospitals were the equivalent of today's tertiary hospitals, while "B" grade hospitals were specialised with less facilities. For example, Cornwall Hospital in Auckland was a geriatric and obstetric hospital.
} 
This amendment finally allowed men to gain exactly the same general nursing qualification as women in that they were now able to become Registered General and Obstetric Nurses. Alongside this was the establishment in 1973 of an experimental programme offering comprehensive nurse education at two polytechnics. This comprehensive programme did not discriminate between men and women students in the curriculum and assisted in the push to remove obstacles in the path to full recognition for men in nursing (Harding). However, there were continued obstacles to the full recognition of men in nursing, one of the major ones being how men in nursing may challenge the accepted notion of masculinity. The following section will explore this aspect. 


\section{Section 2. Gender, Masculinity and Nursing}

\section{The construction of gender and masculinity}

The concept of gender as a socially constructed identity is of relatively recent historical origin. Connell (1995) suggests that an individual constitutes their gender identity not on purely biological difference, but by internalising the social meaning given to that biological difference. Although the terms 'masculinity and femininity' have been used for centuries they are usually used in biological terms to signify gender (Williams, 1995). The nurse according to Miers (2000) is a powerfully gendered symbol because in most parts of the world most nurses are women. Historically, the title 'Nurse' has been (and still is) associated with women. The belief that nursing is an extension of the domestic role of women has been instrumental in establishing nursing, not only as a woman's occupation but also as unskilled and less valued in comparison to those of men (Evans \& Blye, 2003).

Nursing appears to embody all that is the patriarchally constructed view of femininity: passivity, self-sacrifice, devotion and subordination (Gamarnikow, 1991). However, as discussed earlier, nursing was originally seen as a way to reform women's occupational status in Victorian England. This reform became a political strategy that, according to Garmarnikow, was unfortunately taken over by the men of the time to achieve their own ends. Thus, the lesser status of nursing was linked to the place of women in society. Male attendants may have performed similar work, but without the 
public associations of moral respectability and discipline, so important to their female counterparts (Miers, 2000). This stress on the links between nursing and feminine attributes was successfully used to confirm dominant Victorian constructions of femininity. Miers notes the contradiction in accepted notions of Victorian attitudes to masculinity in asylum work during this era. The physical nature of the work and the accepted hierarchical pattern of the working-class male deferring to the authority of the higher class status (the medical man) is suggested by Miers to indicate that men in nursing in the nineteenth century conformed to accepted patterns of masculinity within male hierarchies that are grounded in economic differences. As a profession, nursing has been subordinate to the medical profession, which continues to be dominated by men (David, 2000). Thus men in nursing present a challenge to the gendered order in healthcare (Savage, 1987). Consequently this challenge was easily ignored by simply failing to acknowledge men as nurses. As we have seen in New Zealand, it was not until 1939 that men were permitted to register as Nurses and not until 1978 that men were able to participate in all areas of nursing.

Western thinking is rooted in dualism with masculine/feminine being the exemplar of this. When examining gender, Whitehead (2002) observes many stereotypes that follow this pattern, such as passive/assertive, strong/weak, irrational/rational, gentle/forceful, emotional/distant all of which are often used to differentiate male and female. Nurses purportedly have feminine traits such as being submissive or passive, gentle and 
emotional which may also be held as being weak (Whitehead) or at least that has been a common picture held by society, and one often reinforced by media images. In fact Jinks (1993) suggests that many women in nursing themselves believe that being a good nurse is dependant on innate biological characteristics and socially perceived, stereotypical feminine characteristics.

Nursing in Western society is seen as a feminine occupation and dualistic notions mean it cannot be masculine. If nursing has so strongly been associated with the feminine, what does this suggest about men in nursing? A man in nursing must be as a woman, namely weak, submissive, gentle and emotional. These are not the characteristics that are considered masculine in Western society. Connell (1995) and Whitehead (2002), however, assert that no such thing as a modern masculinity exists. That such a concept is not real and that masculinity is a variable, often idealised product, representative of both the social conditions of the time and the dominant ideology, is often overlooked. This view creates a form of tension between the reality and the idealised image revealing an incompatibility between reality and fantasy. The picture of the typical male New Zealander as a 6'4” rugby playing farmer is a good example of this idealisation, one that most men in New Zealand would not measure up to.

Masculinity is more than sex, gender and desire. There is an active cultural production of masculinity that lies within the wider context of the social organization of the sex/gender role (Haywood \& Mac an Ghaill, 2003). 
According to Kimmel, (2004) masculinity refers to the social roles, behaviours and meanings prescribed for men by the dominant culture in any given society at one time. He describes four different dimensions. The first is that masculinity varies across ethnic cultures. What it means to be a man in New Zealand is different to being a man in China. The second is that the definition of masculinity varies over time in any one country. In other words, what it means to be a man in early $20^{\text {th }}$ century New Zealand is different to what it means to be a man in early $21^{\text {st }}$ century New Zealand. The definition of masculinity is also likely to change over the course of an individual's life. What masculinity means to a young man in his late teens is different to the perception of a middle-aged man, and that too is different to what a man in his 80 's sees as masculinity. Finally, masculinity is understood differently within any given society at any one time. In other words, not all New Zealand men share the same definition of masculinity. Thus, with so many variations and an ever-changing assemblage of meanings and behaviours Kimmel suggests that we refer to masculinities in the plural rather than a well-defined and limited singular.

\section{Hegemonic Masculinity. Its effect on men in nursing and on nursing}

With this recognition of multiple masculinities it is important, according to Connell (1995), to recognize the relations between them so that the analysis does not "collapse into a character typology" (p76). From this he identifies hegemonic masculinity. Hegemonic masculinity is defined as how gender is practiced to legitimise patriarchy and this in turn guarantees the dominant position of men over women as well as over other men. At 
any one time, one form of masculinity rather than the others is culturally exalted. It is thus not a fixed character type that is always the same, but rather the form of contestable masculinity that occupies the hegemonic position in a given pattern of gender relations (Connell). Connell discusses how hegemonic masculinity embodies a currently accepted strategy for defending a patriarchal position. New groups challenge old solutions and construct a new hegemony, but will not overturn male power (Connell). Men in nursing are supposedly an example of this challenge to what has been the acceptable form of masculinity. However, it will be discussed later that men in nursing do not always challenge the current hegemonic masculinity and, for many reasons, in fact support the status quo.

Men who choose nursing as a career, risk challenging the traditional roles of their gender stereotype (Looker, \& Magee, 2000). Boys and girls are socialised into their gender-role, exposed to different role models and provided with different messages about what is appropriate (Muldoon \& Reilly, 2003). According to Connell (1995) all societies have cultural accounts of gender, but not all have the concept 'masculinity'. In the western world, masculinity assumes that one's behaviour results from the type of person one is, with society presenting men with strong stereotypical boundaries concerning masculine or feminine behaviour. Thus an 'unmasculine' person would behave differently to the current embodiment of hegemonic masculinity. For example, Connell notes that this would currently include men who are unable to kick a football or uninterested in sexual conquest, or those that are peaceable rather than violent and/or men 
who are conciliatory rather than dominant. In terms of masculinities in nursing it may be the latter two examples that men may find themselves struggling with the most.

\section{Maintaining masculinity}

Masculinity for men has traditionally been defined by the labour they perform (Connell, 1995). This notion of masculinity means that it may be all right for women to enter traditional men's occupations, but it is still seen as a little quirky that men enter women's traditional roles. It could be hypothesized that as more women cross over into traditional men's work it will push men over into what has usually been defined as women's work. As a result, men in this position might critique and reject traditional hegemonic masculinity. Cross and Bagilhole (2002) and Williams (1995) however, do not think this is likely as both their studies report that men actively maintain traditional male values and do not challenge gender identity. Williams found that men in nursing and other female dominated professions often emphasised their masculinity and attempted to distance themselves from their women colleagues, as a way to legitimise their working in women's jobs. Cross and Bagilhole found in their study of men in non-traditional occupations that the majority of these men tried to maintain a traditional masculinity. This, Cross and Bagilhole likened to men colonising some feminine skills and abilities to be more of a ‘complete man'. Connell sees this as men taking on feminine virtues and adding these to their masculinity. He acknowledges the limitations of any 
project to reform masculinity stating it would only help to modernise patriarchy rather than to abolish it.

The high value associated with men and masculinity in patriarchal culture has contributed to the masculinisation of certain specialties within nursing, which are associated with increased status and pay (Evans, 2004, Gans, 1987). Men are more likely to be found in mental health, intensive care and emergency departments, for example (Armstrong, 2002, Villeneuve, 1994). The trend for men to go into more fast paced 'prestigious' areas of nursing continues to reflect the gendered division of labour within nursing, a division that is grounded in stereotypical notions of masculinity (Evans, 2004). According to Williams (1995) men are pressured into these specialties despite their inclinations otherwise. She calls this the glass escalator effect where men are on an "invisible up and may have to struggle to remain in the lower (i.e. "feminine") levels of the profession”(p12). Examples of this in nursing are paediatric nursing and gynaecological and obstetric nursing. In a unique twist to this, Williams suggests that preventing men from working in the gynaecological and obstetric area could imply that men are above working in this most female identified specialty.

An exploratory study undertaken by Fitzgerald (1995) found that men who entered nursing saw themselves in the unusual position of belonging to two very different groups. In nursing, men belong to the minority group labeled 'male nurse', and in wider society, men belong to the dominant social 
group. Men in nursing are thus a special kind of minority group, as they are either a minority of the dominant social group or minority of the majority. Fitzgerald found that this minority-majority grouping forces men to question who they are as men in nursing. The role of nurse means that men must explore their personal understandings about what it is to be a 'nurse', what it is to be a 'man' within society, and then a 'man in nursing' in society. It would appear from both the literature and my own experience in nursing education that male students of nursing get little assistance with this exploration.

According to Evans (2004) a man's association with nursing compromises his prestige and social status, one that is built up for all men in patriarchal culture and the lack of value associated with nursing has been reflected historically in low salaries. Kauppinen-Toropainen and Lammi (1993) found that men have been less active in crossing the occupational gender barrier than women. One reason they found was that men get fewer material benefits from doing so. In the Finnish part of this study, the men's salaries in non-traditional occupations were lower than the average men's salaries. Interestingly the non-traditional men's salaries were, however, significantly higher than their women counterparts salaries. The conclusion that these authors made, and an observation that Kalist (2002) also made, was that the non-traditional men were likely to benefit in terms of better pay and opportunities when compared to their women peers, but they were not when compared to their men peers in traditional male occupations. Kauppinen-Toropainen and Lammi also found that men reported fearing 
the stigma of working in a female profession. Men who choose nursing as a career risk challenging the traditional roles of their gender stereotype.

In the push for professionalisation in the 1950's and 1960's many sociologists wrote how professionalisation would forever elude the 'semiprofessions' and provided various reasons for this (Williams, 1995). According to Miers (2000), and Williams one of the reasons these sociologists didn't explore was that these 'semi professions' were largely female dominated professions. There was mention of the fact that women were represented in these jobs, but the reasons given were that they were drawn to these jobs rather than consciously making a decision to enter them.

With the desire for professional recognition, many nursing leaders of the 1960's through to the 1970's sought to increase the number of men in nursing as a way to increase the prestige of nursing (Garvin, 1976). Thus there was a deliberate attempt to introduce masculine concepts into nursing at a fundamental level, within the knowledge base of nursing. This was part of an attempt to establish nursing as a profession parallel to, rather than subordinate to, medicine (Austin, cited in Savage, 1987). Austin points to the Salmon Report (cited in Savage, 1987) into healthcare in the UK in the mid 1960's that questioned the ability of women in nursing to act as effective managers. This belief possibly stemmed from traditional western philosophy in which 'reason' is in some sense masculine, so that by implication, women are less rational and more emotional than men. Savage 
(1987) observed that within nursing rationality has been unquestioningly accepted as the appropriate basis for nursing and it is men who are thought to bring a more rational approach. In fact this thinking still exists today. Williams gives examples of Army recruitment posters depicting men in the Nursing Corp with the slogan “an edge on career growth”. Williams states how recent advances in our understanding of what constitutes a profession show us that indeed nursing (as well as other women dominated careers) do possess the requisites for acknowledgement as a profession (Friedson, cited in Williams). However, the idea that nursing is 'women’s work' still exists today and no more justification is required to support this contention, than the fact that very few men are represented in nursing today.

Why did it take so long for men to be accepted as legitimate nurses in

New Zealand? The effects of hegemonic masculinity in

\section{Aotearoa/New Zealand}

James and Saville-Smith (1994) describe New Zealand as having a unique gendered culture that emerged out of the urgent manner in which Britain colonized New Zealand. It developed as a means to cope with the continuous struggles over land, not just between Maori and Pakeha, but also among Pakeha, between propertied and unpropertied and between men and women. The reasons for this may have its roots in historically dominant masculine ideal: patriarchy, marginal masculinities and sexualities, particularly those of non-white men (James and Saville-Smith). 
Connell (1995) describes how the images of male masculinity in Australia have been constructed around images of men, such as the convict shaking his shackled fist, the bushmen plodding down a dusty track, the heroic explorer facing inland, the digger scrambling up the slopes at Gallipoli, the Aussie Rules player, front bars and shearing sheds. Connell notes that there are very few women in this world, but there are very definite images of masculinity whether real or imagined. The similarities in these descriptions with New Zealand are obvious: the pioneer struggling to break in the land, (again) the ANZAC fighting at Gallipoli, the cow cocky in his gumboots, the All Black, 'Pine Tree' Meads, public bars; these are all images that we associate with 'The New Zealander'. Nowhere in this description is there a man who holds a sick person's hand, who calms a crying child, who comforts a son or daughter that has lost an elderly parent, or who helps a person with diabetes to adjust to a different way of life. In other words the man who is a nurse does not fit with our (imaginary) image of what it is to be a man in New Zealand.

So why did the people in charge of both nursing and hospitals in New Zealand decide that nursing would be better off without men? The answer could have been in the making of housework into a science that transformed the role of the wife into a profession in post-colonial times (James \& Saville-Smith 1994). This also contributed to the development of a specific female sphere in the paid labour market, stimulating the growth of nursing, among other things. According to James and Saville-Smith, these occupations where women were protected from direct men's 
competition, became increasingly important as a means through which women could achieve some economic independence and social status.

Many nurses in leadership positions in New Zealand followed international thinking and felt that men were unsuitable for nursing positions (Brown, 1994), perhaps reflecting the hegemonic masculinity of the period. This combined with a view that the nurse was a superior type of woman with greater moral sensibility who needed protection from the more brutal aspects of life meant that men were not seen as essential to the nursing profession.

As we have seen, the UK admitted men into nursing as a way of alleviating post-war nursing shortages and also bringing returned servicemen back into the workforce. New Zealand was in the same position as far as a post-war nursing shortage was concerned (Brown, 1994). However, for some reason men were not considered as an answer to this shortage. Was this part of New Zealand's own hegemonic conception of masculinity? The answer, while difficult to ascertain and beyond the scope of this dissertation, would add to the richness of New Zealand's nursing history.

According to Pringle (2002), thanks to the commodification of rugby, the All Blacks are no longer always seen as depicting traditional masculinity. They can be viewed in women's magazines as caring partners and in selfeffacing television commercials. This has had the effect of softening some of the image of masculinity for many New Zealanders and thus the 
definition of masculinity in mainstream New Zealand is changing. This shift in our national masculinity may make a small contribution to New Zealand men seeing nursing as a more acceptable career choice. What we need is an All Black to be a nurse. If the gay community can have rugby hero Ian Roberts, nursing should have its own All Black hero.

\section{Tokenism: How token men are advantaged in nursing}

Kanters' (1977) concept of tokenism states that the numerical underrepresentation of a group in an occupation, especially those classified by race, gender or ethnicity, will result in discriminatory treatment. Thus all numerical minorities, referred to as 'tokens', in any given occupation will suffer negative job consequences. According to Kanter, minority group members are less likely to be high achievers in the work environment than are the majority group members. When women are placed in token positions men retain their numerical superiority and are able to maintain their gender privilege by restricting a woman's entry, promotion and experiences in the workplace. However, according to Williams (1995) when men are tokens, they are welcomed into the profession, and use their gender privilege to rise quickly within the hierarchy. Williams suggests that this is because men and the qualities traditionally associated with masculinity, are highly valued by organisations that are frequently dominated by men. Any difference from women and associated femininity, is actively claimed and reproduced by token men as a source of advantage and prestige. 
As a comparison to other traditional female occupations, Young and James' (2001) study on the affects of tokenism on men who were flight attendants, found that men were affected negatively by being tokens. In contrast to the women majority they were less attached to the organisation and their attitude to work was affected through lowered self-esteem and poor job fit. Young and James attributed the poor job fit to the nature of the work performed by flight attendants being perceived as highly feminine.

Conversely, Zimmer (1988) found that the effects of tokenism appear to be minimal for men in nursing. Zimmer cited several studies which reported that men in nursing experienced institutional opposition, however, this opposition was not severe enough to present an obstacle to men's continued employment. Likewise Kadushin (cited in Zimmer) concluded from a study into role strain in men who were social workers, that there was considerable advantage in being a male minority in any female profession. It would appear that the effects of tokenism almost disappear when they conflict with traditional gender relationships. When men are tokens, the disadvantages of being 'the few' are minimal and, under many circumstances they turn into advantages. Zimmer advocates that it is society's gender bias that puts men ahead of women in the workplace and suggests that sources of informal power, based on power differences outside the organisation must be considered as well.

Kauppinen-Toropainen and Lammi (1993) noted that women in traditional men's occupations of police and technicians found their colleagues to be 
less supportive and friendly. This contrasts with men in traditional women's occupations, in this case nursing and waiting, who found their colleagues supportive, friendly and were treated as equals. These differences may reflect the disparities in the workplace cultures (i.e. that mens' workplaces tend to be less cooperative than women's ones) (Kauppinen-Toropainen \& Lammi). The differences may also suggest, as these authors point out, the positive treatment that the solo token men in women-dominated occupations receive.

Thus, as Zimmer (1988) states, the experience of being a token in a highly skewed workforce has very different consequences for men and women. The effects of tokenism would appear to virtually disappear when they conflict with traditional gender relationships as men take their gender privilege and sexual power with them into the token situation (Williams, 1995). Tokenism may also be a contributory factor in the fact that men are over-represented in supervisory and administrative positions.

\section{Men in nursing management positions}

It is well known that men are over-represented in senior nursing positions (Cotton, 1998, Williams, 1995, Villeneuve, 1994). In fact nursing is unique in this regard, in that men are over-represented compared to women in management when compared to other women dominated occupations (Williams, 1995). According to Evans (1997), although men and women enter nursing for similar reasons, the societal and cultural expectations placed on men mean that men's career path takes on the traditional 
masculine role that seeks power and influence. This leads to men seeking and obtaining managerial positions (Evans, 1997, Matthews, 2001). According to Evans it is the existence of a patriarchal society that places value on masculine traits that gives men this advantage.

As previously discussed, the term "glass escalator" was coined by Williams (1992) to describe what happens to men who enter predominantly female occupations and to contrast the glass ceiling that limits women's mobility in traditional men's occupations. The glass escalator refers to men's enhanced mobility within these women dominated groups. According to Williams, men entering the mostly female occupations don't bump up against a glass ceiling but rather they ride the glass escalator and have a much easier time being promoted. However, as Williams points out, these opportunities may extend only to those who exhibit conventional masculine characteristics, including a heterosexual orientation.

A consideration in relation to men's 'success' within the profession is the phenomenon of 'over-performance' or 'over-compensation'. Whittock and Leonard (2003) and Zimmer (1988) refer to this as 'heightened visibility', which creates an overwhelming pressure on the minority, in this case men in nursing, to perform successfully to prove that they are worthy. Thus, although men may have a tough time when they enter nursing because their motivation and abilities are scrutinised more than their women counterparts, they generally also find it easier to get ahead (Halford, Savage \& Witz 1997). This is in contrast to women in non-traditional areas 
of employment who are often scrutinised for faults and denied promotion by men (Whittock \& Leonard).

The traditional view once held that men were more suited to management positions in any area because "women generally tend to react to problems and situations in an emotional rather than a rational manner” (Lloyd, cited in Miers, 2000). Thus, in nursing, men were seen as more appropriate for management positions. Roberts (1983) argues that because nursing has been an oppressed group, nurses perceive themselves in terms of the oppressor's view of reality and hence may perceive themselves as having inferior management ability. Women in nursing may just accept that the traditional masculine view of management might exclude themselves, but not their male colleagues (Roberts). This analysis however, may be oversimplifying the motivations of individual nurses who may either include themselves in traditional models of management, or embrace other forms of less masculine forms of management. Miers (2000) sees a nonoppressed, feminist view of managerial skills as enhancing the nurses' awareness of the managerial importance of their own nurturing and supportive skills. This paradoxically, Miers goes on to say, might facilitate men in nursing, who receive support from women colleagues in enhancing their career to develop their own facilitative managerial skills, expertise that might not feature strongly in the masculine management imagery.

Williams (1995) discusses a concept of 'gendered organizations' where cultural beliefs about masculinity and femininity are built into the very 
structure of the working world. On a very basic level this is illustrated in how employers often prefer to hire workers with minimal distractions from their career, such as pregnancy or dependant children. This is not a genderneutral preference. Men fit this description far more easily than women who are traditionally required to shoulder more of the responsibility for additional household responsibilities (Porter, 1992). Thus in nursing, men may be a preferable option to women simply because of this criteria. It has been hypothesised that the rise of men in nursing management may also be due to geographical mobility (Ratcliffe 1996). This is usually because in the traditional household, the man has priority in career development and women have tended to follow their husbands. Williams (1993) found that women in nursing who are married are less likely than single women to pursue advanced degrees in order to apply for promotion. In a market that may value experience from outside the institution, lack of opportunities for geographical mobility serve as barriers to promotion (Ratcliffe). Ratcliffe suggests that within patriarchal social structures the criterion of geographical mobility shrouds collective, irrational exclusion on the basis of gender, and in terms of promotion opportunities, creates a labour market for men. 


\section{Section 3. Being a man in nursing}

\section{Stereotyping: 'All men in nursing are gay'}

Pringle (1993) suggests that any 'feminised' occupation is presumed to draw homosexual men, whether it is hairdressing, fashion or nursing. A firm connection seems to be drawn between gender and sexual preference, and the stronger the sex-typing of the job, the stronger the resulting stereotype. Savage (1987) asserts that the predominant image of the man in nursing is that he is homosexual. As Savage explains, the logic underlying the association between men in nursing and homosexuality suggests that a man who enters nursing has supposedly failed to make his way in a mans world and that now only a women's world is open to him. (I can recall many comments from both patients and colleagues about why I didn't enter medicine as a profession or when was I going to go to medical school).

The man in nursing is thought to be further 'emasculated' by taking on 'women's work' in which he is expected to demonstrate 'feminine' qualities such as caring and being gentle, and be in a position in which he may be subordinate to women (at least until he gets a management position!) Thus, this labeling of all men who are nurses as gay does not represent a tolerant attitude toward gay men, nor is it based on any evidence (Hiekes, cited in Evans and Blye, 2003). The assumption that all men in nursing are gay is, instead, based on patriarchal beliefs about masculinity (Williams 1995). 
According to Dowsett (2003) an understanding of homophobia is central to the understanding of masculinity. Sedgwick (cited in Dowsett, 2003) argues that patriarchy is 'deeply structured' by homophobia, with the bonding between men that is so essential to patriarchy, only sustained through a refusal of the homoerotic. In other words, the link between men under patriarchy can be seen as deeply sexual, precisely because of that denial. This homophobic character of hegemonic masculinity is well documented (Connell, 1995). So then, why is it that men would fear homosexuality? Pronger (cited in Haywood and Mac an Ghaill, 2003) suggests that in our culture, male homosexuality is a violation of masculinity, a denigration of the mythic power of men, an ironic subversion that significant numbers of men pursue with enthusiasm. He also argues that as homosexuality gnaws at masculinity it weakens the gender order. However, because masculinity is at the heart of homoerotic desire, homosexuality is essentially a paradox in the myth of gender.

Holyoake (2001) discusses the 'gossip' in nursing circles and in wider society over the sexual orientation of men in nursing and of their supposed 'effeminacy'. According to Holyoake this gossip is used to support the dominant patriarchal and homophobic culture's attempts to secure its dominance. Daly (1973) suggests that the reason a patriarchal society places low status on homosexual men is because they are perceived as being similar to women, thus these men also occupy an inferior position. In an ethnographic study of men in mental health nursing, Holyoake suggested that, to fit in, the men in nursing must identify as heterosexual so 
as to belong to the dominant, normal, safest group. Holyoake suggests that men in nursing are conditioned to conceal and suppress elements that might be insufficiently manly (whether the individual is heterosexual or homosexual). There is a belief that the man in nursing can be himself but it is Holyoakes' view that this is not so and the opposite is true. He describes this as 'soft masculinity' whereby the man in nursing has a sense of self and thus presents an image that is fashioned within nursing culture and the experiences encountered in clinical practice. However, this notion of soft masculinity has a boundary. According to Holyoake (2002), if a man in nursing goes beyond this and behaves in a non-macho way or is considered too effeminate he is measured against mainstream hegemonic masculinity.

Men appear to encounter more negative criticism from society on entering typical female occupations, with society having difficulty in accepting the image of men as caring, compassionate and gentle. Kadushin (cited in Zimmer, 1988) found in a study of men who were social workers that the negative effects for men in women dominated jobs may be more apparent off the job than on. Cross and Bagilhole (2002) point out that nearly half of the men in their study of men in non-traditional jobs, had at some stage concealed their occupation from their friends and strangers they meet. Fisher (1999) in a study in Sydney into gender issues in nursing found that men in nursing still believed they were stereotyped as gay, both outside and within the profession. Similarly Birse and Lane (2002) suggest that some men in nursing feel they need to prove themselves to be worthy members of the profession and that they have to overcome the enduring stereotype 
that they must be gay. Rallis (1990) found, in informal interviews investigating the perceptions of nurses, that women approved of men as nurses while the majority of men disapproved. Although a small scale study, Rallis concluded that the discrimination for men in nursing came from other men rather than women. This study supports Kimmels (2004) assertion that discrimination and homophobia usually come from other men and that men most often fear other men because of the competitive nature of masculine relationships.

Williams (1993) suggests that the stigma associated with homosexuality leads some men to emphasize or even magnify their masculine qualities. In a qualitative research project using focus groups with men who were undergraduate nursing students, Kelly, Shoemaker and Steele (1996), found that all participants reported that nursing is viewed as a women's profession. Several participants stated a fear of being perceived as unmanly by their peers or by clients. These beliefs fostered a view among the men that the nursing profession is a threat to their masculinity. Subsequently, these men felt a need to show their wedding ring or to mention their wife and children in order to acknowledge their heterosexuality. According to Mangan (1994) the labeling of men in nursing as effeminate or homosexual can be interpreted as a social control mechanism that redefines nursing as women's work. This labeling of men in nursing as gay signifies that they are different from other men, that they are some how less masculine. 
Evans (1997) describes a gender dynamic in nursing where men have a need to separate the masculine from the lesser-valued feminine. She states that men in nursing do this by employing strategies that allow themselves to be distanced from their women colleagues and the female image of nursing itself, so as to elevate their own prestige and power. It is thought that they are "aided in this task by patriarchal cultural institutions that create and perpetuate male advantage, as well as by women nurses who, consciously or unconsciously, nurture the careers of men colleagues" (Evans, p227). Consequently, as a result of these attitudes and perceptions, it is clear why men who were students of nursing could have difficulty adjusting to their role. Fisher's (1999) study, exploring the attitudes of male and female engineering students, and male and female nursing students, found that most respondents, which included men in nursing, male engineers, and women in nursing, believed that nursing was an appropriate career choice for men. However, $69 \%$ of the men in nursing felt they were stereotyped as low achievers or 'feminine-like'.

It is not the sexual orientation of any given person that has been explored here, but rather it is the gender stereotype and societal notions of what is acceptable masculinity that is the issue. For the individual man in nursing it is not only this stereotype he must contend with but also other factors such as the concept of caring and the meaning that nursing attaches to this. 


\section{Learning to Care}

Recently there has been interest in how caring relates to gender and the possible differences in the learning or expression of caring as it relates to the student, educator, or recipient of care (Cotton, 1998). In a society that largely defines women as the natural carer, 'caring about' precedes 'caring for' with the two always viewed together. Masculine definitions, on the other hand, separate 'caring for' and ‘caring about' (Milligan, 2001). The two concepts are not generally seen to coexist, but where they do coexist, the individuals concerned are seen as atypical because they do not fit the stereotypical role behaviour of men (Dalley, cited in Fitzgerald, 1994).

With the development of grand theories of nursing in the 1950's to 1970's, the concept of caring was given a central status in many of those theories (for example Johnson \& Watson as cited in Bullough, 2001). Although for men this was not a problem it was the implementation that caused issues. One faction according to Bullough interpreted caring as a uniquely feminine quality. By implication, caring was something that men (as males) were not especially qualified to do. Bullough adds that although this was not stated anywhere as explicitly as this, it nonetheless did contribute to men's uneasiness. Whilst the majority of women in nursing may not hold this view, there is evidence that there are women who will not recognise a man as a nurse on the basis of gender only (Bullough, Poliafacio, 1998, Paterson et al, 1995). This is despite the fact that current research indicates that caring is not particularly confined to women, and that there is a tremendous overlap of abilities between most men and 
women (Ekstrom, 1999; Lodge et al, 1997; Bullough). MacDougall (1997) asserts that men do have the ability to care, but that due to the effects of hegemonic masculinity may find difficulty in demonstrating caring. Thus the emphasis that nursing places on caring can be an issue for some men who attempt to retain hegemonic masculinity (Bullough).

Recognition that caring is a culturally constructed concept challenges men in nursing to examine the foundations on which their beliefs about caring are constructed (Fitzgerald, 1995). An exploration from a critical perspective may be useful in verifying the assumptions around this. In an exploratory study, Fitzgerald found that men acknowledged that on entering nursing the idea of having to 'care for' or provide direct hands-on care was somewhat unclear, but nonetheless they believed they could learn. The study participants also recognised that despite an initial focus on 'caring about' rather than 'caring for', they saw learning 'to care' as a lifelong process of personal and professional development involving both men and women. Rather than an ability to care being linked to the gender descriptor male/female, men saw the ability to care as a question of individuality. Fitzgerald found that for men the task appeared to be directed more toward identifying and developing the 'caring for' component of their individual personalities, a task that requires them to challenge the traditional stereotypes of men as carers. The notion of the nurse as 'carer' brings about notions of a peaceful and passive person which contrasts with the current hegemonic view of masculinity that sees men as aggressive and competitive. For men who were students of nursing, recognising that caring 
is a learnt behaviour as opposed to an essentialised characteristic of traditional sex roles, may challenge them to critically examine the foundations on which their beliefs about caring are constructed.

In a study of male nursing students' perception of their clinical experience, Struebert (1994) found that men who were nursing students dreaded how women clients may feel about having them as nurses. They consequently struggled with learning appropriate ways to care and touch that would avoid the problem of clients thinking that a man was seducing them. Men in nursing who were participants in Evan's (2002) study told how they were aware of their own vulnerability when they touched patients. According to Paterson et al (1996),' the experiences of learning how to care, for men who are students of nursing, is often characterised by internal conflict. Paterson et al found that the participants' experiences of being different or being a minority in the programme were significantly related; not to discrimination because of gender, but to a lack of awareness in the educational programme of the unique needs of male students and their coming to terms with the distinctive expectations of a nurse. The participants in this study identified a number of gender-specific issues in the lived experience of men who were students as they learn to care as nurses. If, as McDougall (1997) suggests, men are entering the profession for the same reasons women are, which include a desire to care for others, then a lack of preparedness by Schools of Nursing for the gender issues men who were nursing students encounter is an issue that needs to be addressed. 
The literature around acceptance by patients of the care given by men in nursing is mainly centred on gynaecology and obstetric patients (such as Lodge et al, 1997) who are obviously female. Little appears to be written on acceptance by men nursed by men. As has been discussed earlier, one of the struggles that men in nursing have is the perception that they are gay. Patterson et al (1996) made a reference to this in a discussion about men nursing students being concerned about the appearance of 'coming on' to men patients when they touch them. Evans (2002) states that this is a surprising omission considering the stigmatising label of gayness associated with men in nursing and a tendency of men, not women, to be homophobic. This is an important area that requires further research.

According to Evans (2002) the concept of therapeutic touch as described in some nursing theories and nursing texts can be problematic for men in nursing. Evans discusses the suggestion that unlike women's touch, which is considered a normal extension of women's traditional caregiver role, men's touch is often surrounded by suspicion. The suspicion implies men's motives for touching are not comfort or care-orientated but sexual in nature. Evans adds that for men nurses who are required to be involved in intimate touching of patients, there is a possibility for gender stereotypes to create complex situations of acceptance, rejection and suspicion. Evans and Blye (2003) give the ironic situation of men, labeled as gay simply because they are nurses, potentially being suspected of inappropriately touching or seducing women patients. 
Many of the issues explored so far in this dissertation have meant that many men have shied away from embarking on a nursing career. These hurdles can make it difficult for men just to apply to, let alone survive, the undergraduate nursing programme (Villeneuve, 1994). So how do we encourage men to become nurses? To do this it may be beneficial to explore issues of recruitment and retention of men in nursing. 


\section{Section 4. Recruiting and retaining men in nursing}

\section{Why men enter nursing}

The reasons why men enter nursing has been looked at extensively (Squires, 1995, Boughn and Lentini, 1994, Perkins, Bennett \& Dorman, 1993), with the conclusion that men enter and stay in nursing for much the same reasons as women (Villeneuve, 1994). Mason (1991) gives personal accounts of why men have entered nursing and offers the conclusion that nursing gives men the opportunity to make a difference in a person's life thus gaining emotional rather than financial rewards.

Lo and Brown (1999) explored the perceptions of male and female nursing students towards nursing as a career. They found that male students were influenced by the availability of career opportunities and the nature of the clinical experience perceived through their nursing education, rather than issues of power and control within the profession. Results indicated that nursing was attractive because of job opportunities, security, diversity, desire to help people and promotion.

Boughn (2001) explored the reasons why both men and women choose nursing and identified three constructs. These were caring, power and empowerment, and practical motivation. Boughn found that both men and women students had a comparable commitment to caring for patients with both groups being clearly motivated by their desire to care for others. The data, however, showed some differences within the construct of power. The 
difference was in regard to empowering others. Women were more interested in empowering others while men were more interested in empowering the profession. Differences emerged between men and women in regards to practical motivation. All male participants indicated that they chose nursing because they expected a good salary and earning power. They saw nursing as a practical choice for achieving this end. All but four of the 16 women students, however, did not cite financial considerations as being important to them. Boughn suggests that these differences should be seen not as diametrically opposed, but as complementing each other. It would be seen then that nursing education could encourage men and women to incorporate these different ways of thinking into the other's professional values.

As highlighted earlier, a barrier to men entering nursing is the challenge it presents to hegemonic masculinity in that men who choose nursing as a career, risk challenging the traditional roles of their gender stereotype. There are also issues of low economic status, pay and value given to nursing in comparison to so-called male occupations (Meadus, 2000, Villeneuve, 1994). Within society nursing is recognised as a female profession and women's roles continue to be less valued as reflected in social status and financial compensation (Jacox, cited in Meadus). Indeed, Meadus sees one of the main barriers keeping men away from entering nursing is the "well-entrenched societal stereotypes associated with nursing” (p.12). 
According to Struebert and O'Toole (1991) there has been a reasonable amount of literature written over the past 10 years about men in nursing from different angles. Much of this has focused on stereotyping, role strain and career choice. Struebert and O'Toole note that whilst these are appropriate topics of research, they tend to repeatedly document that men in nursing, in general are older, married, pursuing nursing as a second career, and have a history of military service. As these authors state, simply continuing to document these demographics will not increase the number of men who enter nursing or assist in retaining them within nursing.

Struebert and O'Toole (1991) found that there was little research examining men's perceptions of nursing academia as well as little scholarship on which variables might enhance successful programme completion or deterrent to the same. Villeneuve (1994) stated that nursing and nursing education has done little to both attract men into nursing and to retain them once registered as Nurses. It would appear that little has changed as Evans in 2004 alludes to the same issues. This may however, be shifting slowly. Good examples of educational institutes attempts to attract men are the Oregon Centre for Nursing in the United States, recruitment poster with the heading “Are You Man Enough to be a Nurse” (Trossman, 2002), and also the recruitment advertisements in 2003 by the University of Auckland's Department of Nursing, which portray a man who is a nurse.

Villeneuve (1994) suggests that the female-nursing link seems stronger than in any other occupation, and nursing has not been very adaptable 
when it comes to accommodating those who are not what Curran (cited in Villeneuve, 1994) referred to as 'nice white women'. As students, men not only have few male peers, they also have few other men to model their practice on both within the faculty and within practice. Lecturers address the class as 'girls' and test question that refer to the nurse as 'she' can go toward making male students feel excluded or 'invisible' (Poliafacio, 1998). For men entering nursing education, this is an issue that many describe as confusing (Paterson et al, 1995); and one that requires support and assistance to help them become enculturated into nursing (Milligan, 2001).

In a descriptive study using focus groups, Kelly, Shoemaker \& Steele (1996) made similar findings. Men often felt isolated and lonely at times due to few male classmates, few male Registered Nurses and no or few faculty role models. These participants also noted that the noun 'Nurse' was generalised to the female sex by instructors who seemed unaware that such generalisations excluded men who are nurses. These authors suggest that retention could be enhanced if education and practice settings were aware of the tendency to identify male nursing students as different and that they were therefore isolating them by this categorisation. The participants in Milligan's (2001) study into men in nursing and the concept of care, felt the influence of gender through expectations placed upon them, and were sensitive to the gender perceptions of patients and their significant others. 
An exploration of gender within nursing education and nursing practice may also be helpful to give both men and women students an understanding of the issues involved (Evans, 2004, Milligan, 2001). Harding (2003) suggests that nursing education has tended to focus gender studies on women while ignoring issues of gender in relation to men. At present little time is allocated within undergraduate education to a sufficient exploration of this issue (Evans, personal communication, 2004).

Part of any retention strategy must also include an exploration of what can be done to support men who both enter into nursing education and who then enter the Registered Nurse workforce.

\section{Support}

There are, according to Kelly, Shoemaker and Steele (1996), few qualitative studies that explore the needs, frustrations and problems that men experience in the socialisation process of becoming a nurse. Birse and Lane (2002), Kelly, Shoemaker and Steele (1996), Fitzgerald (1995), and Okrainec (1994) describe how settling into a predominantly female environment and learning to interact with women on a collegial level may be difficult for many men. Two former students of an undergraduate nursing programme from a New Zealand university suggest that more could be done to support male students and to assist them to integrate into the culture of nursing (Birse \& Lane, 2002). Anecdotal evidence taken from discussion with other male nursing students would suggest that there are difficulties faced by students in regard to settling into a programme of 
study. At present, very little is known as to what it is like to be a male student in an undergraduate nursing degree programme.

Ooijen and Charnock (1994) suggest that men are socialised to provide and protect their families, not to be close and intimate. Most women gain emotional support from their women friends, and give emotional support to their partner. Men's relationships tend to be structured by dominance and hierarchy (Ooijen \& Charnock). How then do men fare in a women's environment such as nursing where close intimate, emotionally supportive relationships are the norm? In a qualitative study using focus groups Kelly, Shoemaker and Steele, (1996) looked at male nursing student's motivational factors, barriers and frustrations. Participants, who saw the University as being supportive on the whole, reported challenges. The students described the stress and pressure of school, the feelings of selfdoubt and isolation, and the perceptions of being treated differently. A prevalent feeling was that they had few registered nurse or male faculty role models. Several students felt they were not included in conversations with other women student nurses unless they made the first move, and those clinical groups, which included other men, made the clinical experience easier.

Some authors have argued for the inclusion of more role models for male students in clinical practice (Patterson et al, 1996, Kauppinen-Toropainen and Lammi 1993). Patterson et al (1996), found in a study on how male student nurses learnt to care, that role models could be either male or 
female and that both had a positive effect on their learning. However, Burrows (2000) is wary of this practice for two reasons. Firstly that the values and life experiences of some role models are so far removed from their own life experiences that the 'rub-off' effect is negligible. Secondly, that the concept of role modelling does little to challenge the notion of how gender and masculinity is defined within our society.

Milligan (2001) considers that there should be structures and systems in place for clinical supervision in nursing education that take into account the fact that men may be reluctant to seek support, or may feel pressured into a role, which encourages them to make do without support. The socialisation process, put simply in terms of the adage 'men don't cry', may disable particular men from seeking support. This socialisation process brings us back to the question of how our society views both gender and masculinity. 


\section{Conclusion}

The exploration in this dissertation has concluded that masculine and feminine qualities are not inherent in men and women respectively. Rather they are the product of social beliefs and practices. Thus there is, no question that men can do the work usually assigned to women. As Savage (1987) points out, there is no built-in reason why, for example, women should be better at caring and men better at leading. The basic problem and challenge, however, is to get men to do this work alongside women, without fear or derision. We should be attempting not to balance supposedly masculine and feminine qualities, but to challenge the assumption that particular qualities are predominantly masculine or feminine. There is a certain irony in the fact that in many instances there is little connection between the jobs nurses do and our current construction of femininity.

For many men in nursing their performances of masculinity have had to be carefully managed to minimise negative consequences for themselves. If they conform to stereotypes of hegemonic masculinity they are open to accusations of being sexually exploitative or abusive. Alternatively, if they don't measure up to masculine expectations; they may not be considered masculine enough, and then are open to accusations of being labelled as a homosexual. As has been highlighted, one of the major reasons for there continuing to be so few men in nursing is the challenge it presents to hegemonic forms of masculinity. What is needed then is not a reproduction 
of the same hegemonic masculinities or a masculinisation of nursing but a challenge to the patriarchal forces that allow this to continue. This would allow those men to feel comfortable in their expression of nursing, allowing them to focus on their own valuable contribution to nursing regardless of their sexuality.

Today's notion of masculinity is changing from what it was 20-30 years ago and it will continue to change as both men and women challenge hegemonic notions of masculinity. It is important, however, that we in nursing challenge it appropriately so as not to merely replace one hegemony with another. Raising awareness of this concern in such forums as nursing education may be one way to prevent this from happening. We need to educate the future generation of nurses on issues of gender, and how these are played out in our society. It is the meaning of masculinity that must be challenged if any real inroads toward sexual integration can be attained.

Greater awareness of how hegemonic masculinity and notions of gender have historically affected, and continue to affect, the development of nursing is important. Nursing education to date has tended to focus gender studies on women while ignoring issues of gender in relation to men. Exploring gender issues from a wider perspective and perhaps taking into account perspectives from other academic disciplines such as sociology may assist all nursing students in exploring masculinities and its effects on both society and the profession. 
The myth that men in nursing are somehow less masculine also needs to be challenged further. These notions could be contested in the classroom, in nursing journals and literature, and through professional nursing organisations. More could be done in changing the gendered image of nursing in the media. This is starting to happen now with television shows such as Shortland Street, portraying men as nurses (and interestingly those characters are not in nursing management positions).

Men coming into nursing often struggle with issues such as the potential challenge to their own personal concept of masculinity in a traditional women's occupation and of being a minority, often for the first time in their lives. One way to assist these students in adjusting is for more men who are nurses to play a greater part in nursing education. Their presence would provide not only a confirmation that men have a legitimate place within nursing; they would also provide support and encouragement from a unique perspective and experience that their women colleagues may not be able to offer male students.

An idea put forward by Anderson (cited in Brady \& Sherrod, 2003) to decrease the gender imbalance and encourage men to enter nursing, is to redefine the title "nurse” as a non-gender caregiver. This renaming of a hard-won and respected title may take much convincing with both nurses and the general public. However, a debate on the title 'Nurse" and its 
association with the submissive and sexualised woman, could add to the discussion within the profession on gender issues for both men and women in nursing.

Today, nursing is just awakening to the gender imbalance within its workforce and is making some steps toward addressing this issue. There is still someway to go to where we are at the point where men are better represented within nursing. Significant barriers still exist both within the profession and outside it, as has been explored in this dissertation. It is important however, as Evans and Blye (2003) state, that nursing should not fall into the poor boy trap, placing all men in nursing in a victim category and disadvantaged in relation to women. This view would merely legitimise gender equity interventions that are narrowly focused on promoting interests of men and would fail to recognise male privilege. The challenge within nursing (as well as other female dominated professions) is to address the issues for men yet at the same time not to disadvantage women.

If nursing is to reflect the population it serves then it must encourage more men to be a part of the profession. However, the recruitment of men into nursing should not be seen as a panacea for the current nursing shortage and it should not be to the detriment of women in nursing. Although this dissertation highlights some issues for both men in nursing and nursing itself, further insights and research is vital if nursing is to develop not only 
recruitment strategies focused on men, but more importantly, retention strategies that address current gender relations that affect all nurses' lives. This is the challenge for future nursing research. 


\section{References}

Armstrong, F. (2002). Men in nursing. Australian Journal of Nursing 9(11), 24-27.

Birse, J., \& Lane, P. (2002). What do men bring to nursing? Kai Tiaki, Nursing New Zealand, 11, 20-21.

Boughn, S. (2001). Why women and men choose nursing? Nursing and Health Care Perspectives, 22(1), 14-19.

Boughn, S. \& Lentini, A. (1994). Why do men choose nursing? Journal of Nursing Education, 38(4), 156-161.

Brady, M., \& Sherrod, D., (2003). Retaining men in nursing programs designed for women. Journal of Nursing Education, (42)4, 159-165.

Brown, B., Nolan, P., \& Crawford P. (2000). Men in nursing: Ambivalence in care, gender and masculinity. International Journal of Nursing History, 5(3) 4-13.

Brown, M. (1994). Male nurse training. In D. Masters, B. Smith, \& M. Brown, (Eds.). Nurses of Auckland. The history of the General Nursing Programme in the Auckland School of Nursing. (pp. 127138). Hong Kong. The authors.

Brown, R. \& Stones, R. (1973). The male nurse. London: G. Bell and Sons.

Bullough, V. (2001). Finally we have arrived. Men in nursing. In J. McCloskey Dochterman, and H. Kennedy Grace (Eds.) Current issues in Nursing (6 $6^{\text {th }}$ ed.) (pp.504-511) St Louis, Mosby. 
Burrows, L. (2000). Old games in new rompers? Gender issues in New Zealand physical education. Journal of Physical Education New Zealand, 33(2), 30-36.

Connell, R. (1995). Masculinities. St Leonards, Australia: Allen \& Unwin.

Cotton, S. (1998). Gender issues. In M. Burkhardt, \& A. Nathaniel, (Eds.) Ethics and Issues In Contemporary Nursing. New York: Delmar.

Cross, S., \& Bagilhole, B. (2002). Girls' jobs for the boys? Men, masculinity and non-traditional occupations. Gender, Work and Organisation, 9(2), 204-226.

Daly, M. (1973). Beyond God the father: Toward a philosophy of women's liberation. Boston: Beacon Press.

David, B. (2000). Nursings gender politics: Reformulating the footnotes. Advances in Nursing Science, 23(1) 83-93.

Dowsett, G. (2003). Masculinity, (homo)sexuality and contemporary sexual politics. In S. Thomsen \& M. Donaldson, (Eds.) Male Trouble: Looking at Australian Masculinities. Melbourne: Pluto.

Egeland, J. \& Brown, J. (1988). Sex role stereotyping and role strain of male registered nurses. Research in Nursing and Health, 11, 257-267.

Ekstrom, D. (1999). Gender and perceived nurse caring in nurse-patient dyads. Journal of Advanced Nursing, 29(6). 1393-1401.

Evans, J., (1997). Men in nursing: Issues of gender segregation and hidden advantage. Journal of Advanced nursing 26(7), 226-231. 
Evans, J., (2002). Cautious caregivers: gender stereotypes and the sexualisation of men nurses touch. Journal of Advanced nursing 4(4), 441-448.

Evans, J. (2004). Men nurses: a historical and feminist perspective. Journal of Advanced Nursing 47(3), 321-328.

Evans, J., \& Blye, F. (2003). Contradictions and tensions: Exploring relations of masculinities in the numerically female-dominated nursing profession. Journal of Men's Studies. 11(3), 277-286.

Fisher, M. (1999). Sex role characteristics of males in nursing. Contemporary Nurse, 8(3), 65-71.

Fitzgerald, L. (1995). Culturing a ‘male nurse’ role. In G. Gray, R. Pratt, \& J. Macklin, (Ed) Issues in Australian Nursing 4. (pp.191-205). Melbourne: Churchill Livingstone.

Gamarnikow, E. (1991). Nurse or woman: Gender and professionalism in reformed nursing 1860-1923. In P. Holden, \& J. Littlewood, Anthropology and Nursing. (pp. 151-167). London: Routledge.

Gans, J. (1987). Men’s career advantages in nursing: The principle of the peter. Current Research on Occupations and Professions. 4(2), 181198.

Garvin, B. (1976). Values of male nursing students. Nursing Research, 25(10) 356-361.

Girard, N. (2003). Men and nursing. AORN journal, 77(4), 728-730

Groff, B. (1984). The trouble with male nursing. American Journal of Nursing, 84(1), 62-3. 
Halford, S., Savage, M., \& Witz, A. (1997). Gender, careers and organisations. London: Macmillan Press Ltd.

Haywood, C., \& Mac an Ghaill, M. (2003). Men and masculinities. Philadelphia: Open University.

Harding, T. (2003). Addressing the problem of masculinity. Kai Tiaki, Nursing New Zealand, 9(4), 2.

Harding, T. (2003a). Male nurses - the struggle for acceptance. Kai Tiaki, Nursing New Zealand, 9(4), 17-19.

Hoff, L. (1991). Human abuse and nursing response. In P. Holden, \& J. Littlewood. Anthropology and Nursing. (pp.85-109). London: Routledge.

Holyoake, D. (2001). The Male Nurse: Addressing the myths of maleness in nursing. Wiltshire: APS Publishing.

Holyoake, D. (2002). Male identity in mental health nursing. Nursing Standard, 16(48), 33-37.

Ironside, P. (2001). Creating a research base for nursing education: An interpretative review of conventional, critical, feminist, postmodern, and phenomenologic pedagogics. Advances in Nursing Science, 23(3), $72-87$.

James, B. \& Saville-Smith, P. (1994). Gender, Culture and Power ( $2^{\text {nd }}$ ed.). Auckland: Oxford University.

Jinks, A. (1993). A study of attitudes to gender and nursing stereotypes in newly recruited student nurses. Nursing Education Today, (13)4, 287294. 
Kalist, D. (2002). The gender earnings gap in the RN labour market. Nursing Economics, 20(4), 155-162.

Kanter, R. (1977). Men and Women of the Corporation. New York: Basic Books.

Kauppinen-Toropainen, K., \& Lammi, J. (1993). Men in female dominated occupations: A cross-cultural comparison. In Williams, C. (Ed.) Doing “womens work": Men in non-traditional occupations. (pp. 91112). London: Sage.

Kelly, N., Shoemaker, M., \& Steele, T. (1996). The experience of being a male student nurse. Journal of Nursing Education, 35(4), 170-174.

Kimmel, M. (2004). Masculinities. In M. Kimmel, \& A. Aronson, (Eds) Men and masculinities: A social, cultural and historical encyclopedia. (pp.651-658). California: ABC-CLIO.

Lo, R., \& Brown, R. (1999). Perceptions of nursing students on men entering nursing as a career. Australian Journal of Advanced Nursing, 17(2), 36-41.

Lodge, N., Mallet, J., Blake, P., \& Fryatt, I. (1997). A study to ascertain gynaecological patients perceived levels of embarrassment with physical and psychological care given by female and male nurses. Journal of Advanced Nursing, 25(6), 893-907.

Looker, E. D. \& Magee, P. A., (2000). Gender and work: The occupational expectations of young women and men in the 1990's. Gender Issues, 18(2), 74-88.

MacDougall, G. (1997). Caring - a masculine perspective. Journal of Advanced Nursing, 25(6), 809-813. 
Mackintosh, C. (1997). A historical study of men in nursing. Journal of Advanced Nursing, 26, 232-236.

Mangan, E. (1994). Private lives. Nursing Times, 90(14), 60-64.

Mason, P. (1991). Jobs for the boys. Nursing Times, 87(7), 26-28.

Matthews, S. (2001). Registered male: a discussion on men in the nursing profession. Canadian Nurse, 11(2-3), 231-235.

Meadus, R. (2000). Men in nursing: Barriers to recruitment. Nursing Forum, (35)3, 5-13.

Miers, M. (2000). Gender Issues and Nursing Practice. Basingstoke: MacMillan.

Milligan, F. (2001). The concept of care in male nurse work: An ontological hermeneutic study in acute hospitals. Journal of Advanced Nursing, 35(1), 7-16.

Muldoon, O. \& Reilly, J. (2003). Career choice in nursing students: Gendered constructs as psychological barriers. Journal of Advanced Nursing, 43(1), 93-100.

O’Connor, T. (2003). From segregation to integration-One male nurses journey. Kai Tiaki Nursing New Zealand, 9(4), 20-1.

Okrainec, G. (1994). Perceptions of nursing education held by male nursing students. Western Journal of Nursing Research, 16(4), 94107.

Ooijen, E. \& Charnock, A. (1994). Sexuality and patient care: A guide for nurses and teachers. London: Chapman-Hall 
Patterson, B., Crawford, M., Saydak, M., Venkatesh, P., Tschikota, S., \& Aronowitz, T. (1995). How male nursing students learn to care. Journal of Advanced Nursing, 22(3), 600-609.

Perkins, J., Bennett. D., \& Dorman, R. (1993). Why men choose nursing. Nursing and Health Care, 14(1), 34-38.

Polifacio, J. (1998). Nursings gender gap. $R N$, 38(1), 39-42.

Porter, S. (1992). Women in a women's job: The gendered experience of nurses. Sociology of Health \& Illness, 14(4), 510-527.

Pringle, R. (2002). Living the contradictions: A Foucauldian examination of my youthful rugby experiences. In H. Worth, A. Paris, \& L. Allen (Eds.). The Life of Brian: Masculinities, Sexualities and Health in New Zealand, (pp58-72). Dunedin: University of Otago Press.

Pringle, R. (1993). Male secretaries. In C. Williams (Ed.). Doing “women’s work”: Men in non-traditional occupations. (pp128-151). London: Sage.

Rallis, S. (1990). I want to be a nurse, not a stereotype. $R N$, 53(4), 160.

Ratcliffe, P. (1996). Gender differences in career progress in nursing: towards a non-essential structural theory. Journal of Advanced Nursing, 23(2), 389-395.

Roberts, S. (1983). Oppressed group behaviour: Implications for nurses. Advances in Nursing Science, 5(4), 21-30.

Savage, J. (1987). Nurses, gender and sexuality. London: Heinemann.

Squires, T. (1995). Men in Nursing. RN, 58(7), 26-28. 
Streubert, H. (1994). Male nursing students perceptions of clinical experience. Nurse Educator, 19, 28-32.

Struebert, H., \& O’Toole, M. (1991). Review of research on male nursing students. In P. Baj, and G. Clayton, (Eds.). Review of Research In Nursing Education, Volume IV. (pp.31-50) New York: National League for Nursing.

Trossman, S. (2002). Caring knows no gender. American Journal of Nursing, 24(5), 65-67.

Villeneuve, M.J., (1994). Recruiting men in nursing: A review of the nursing literature. Journal of Professional Nursing, 10(4), 217-228.

Whitehead, S. (2002). Men and Masculinities. Cambridge, UK: Polity.

Whittock, M., \& Leonard, L. (2003). Stepping outside the stereotype: A pilot study of the motivations and experiences of males in the nursing profession. Journal of Nursing Management, 11, 242-249.

Williams, C. (1992). The glass escalator: Hidden advantages for me in the female professions. Social Problems, 39, 253-267.

Williams, C. (1993). Introduction. In C. Williams. (Ed.). Doing “women’s work”: Men in non-traditional occupations. (pp.1-10) London: Sage.

Williams C. (1995). Still a mans world: Men who do women's work. Berkeley, California: University of California.

Young, J., \& James, E. (2001). Token majority: The work attitudes of male flight attendants. Sex Roles, 45(5), 299-319.

Zimmer, L. (1988). Tokenism and women in the workplace: The limits of gender-neutral theory, Social Problems, 35(1), 64-77. 